\title{
Clavis et notulae ad genera speciesque Scrophulariacearum in Japonia sponte crescentium nec non cultarum.
}

auctore

\section{Masatomi Furumi.}

Hoc opusculum est contractio operis "Conspectus omnium generum et specierum in Japonia (Hondo, Shikoku, Kyūshū et Yezo)" dicti, quod, mense Septembrio anni 1914 ductu illustrissimi Professoris J. Matsumuræ incepi, mense Junio anni 1915 complevi. Materiæ quibus investigationis meae confeci maxime in herbario Universatis Imperialis Tokyoensis serverantur.

Clavis Generum.

Aestivatio corollae imbricato-bilabiata,

$1\left\{\begin{array}{lllllllllllll}\text { labio postico exteriore } \ldots & \ldots & \ldots & \ldots & \ldots & \ldots & \ldots & \ldots & \ldots & \ldots & \ldots & \ldots & 2\end{array}\right.$

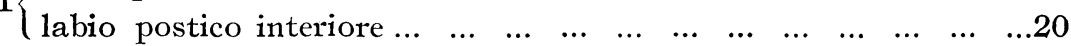

(Folia vulgo alterna, corollae tubo brevissimo vel subnullo. Stamina antherifera 5 , plantae cultae $\ldots$...

2 Folia opposita saltem inferiora, vel verticillata, stamine quinto $\begin{array}{llllllllllll}\text { postico sterile vel subnullo } & \ldots & \ldots & \ldots & \ldots & \ldots & \ldots & \ldots & \ldots & \ldots & \ldots & 3\end{array}$

Corolla saccata v. calcarata, capsula uni vel pluri-valvulato

$3\left\{\begin{array}{lllllllllllllllll}\text { dehiscens } & \ldots & \ldots & \ldots & \ldots & \ldots & \ldots & \ldots & \ldots & \ldots & \ldots & \ldots & \ldots & \ldots & \ldots & \ldots & 4\end{array}\right.$

$\begin{array}{lllllllllll}\text { Corolla non saccata vel calcarata } & \ldots & \ldots & \ldots & \ldots & \ldots & \ldots & \ldots & \ldots & 6\end{array}$

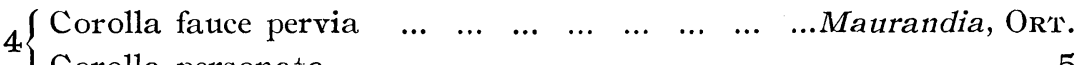

$4\left\{\begin{array}{lllllllllllllll}\text { Corolla personata } & \ldots & \ldots & \ldots & \ldots & \ldots & \ldots & \ldots & \ldots & \ldots & \ldots & \ldots & \ldots & \ldots & 5\end{array}\right.$

$5\left\{\begin{array}{llllllllll}\text { Corolla saccata } & \ldots & \ldots & \ldots & \ldots & \ldots & \ldots & \ldots & \ldots & \text { Antirrhinum, Linn. }\end{array}\right.$

$\left\{\begin{array}{lllllllllll}\text { Corolla calcarata } & \ldots & \ldots & \ldots & \ldots & \ldots & \ldots & \ldots & \ldots & \ldots & . \\ \text { Linaria, Juss. }\end{array}\right.$

${ }_{6}\left\{\begin{array}{lllllllllll}\text { Inflorescentia cymoso-paniculata } & \ldots & \ldots & \ldots & \ldots & \ldots & \ldots & \ldots & \ldots & \ldots & 7\end{array}\right.$

$6\left\{\begin{array}{lllllllllll}\text { Inflorescentia vulgo simplex } & \ldots & \ldots & \ldots & \ldots & \ldots & \ldots & \ldots & \ldots & \ldots & \ldots 11\end{array}\right.$

Capsula loculicide dehiscens, arbores, labio postico bilobatore-

$7\left\{\begin{array}{cccccccccccc}\text { flexo } & \ldots & \ldots & \ldots & \ldots & \ldots & \ldots & \ldots & \ldots & \ldots & \ldots & \ldots \\ \text { Pawlownia, S. et. Z. }\end{array}\right.$

$\begin{array}{llllllllllll}\text { Capsula septicide dehiscens } & \ldots & \ldots & \ldots & \ldots & \ldots & \ldots & \ldots & \ldots & \ldots & \ldots & 8\end{array}$ 
$8\left\{\begin{array}{l}\text { Frutex, corollae tubus subcylindricus gracilis ............ Russclia, JAcQ. } \\ \text { Herbae annuae v. perennes, staminodium squamaeformia v. lingui- }\end{array}\right.$ $\begin{array}{lllllllllllllllll}\text { formia } & \ldots & . . & \ldots & \ldots & \ldots & \ldots & \ldots & \ldots & \ldots & \ldots & \ldots & \ldots & \ldots & \ldots & \ldots & 9\end{array}$

$9\left\{\begin{array}{lllllll}\text { Staminodium linguiformia } & \ldots & \ldots & \ldots & \ldots & \ldots & \text { Pentstemon, Limer. }\end{array}\right.$

$\left\{\begin{array}{lllllllllll}\text { Staminodium squamaeformia } & \ldots & \ldots & \ldots & \ldots & \ldots & \ldots & \ldots & \ldots & \ldots & \ldots 10\end{array}\right.$

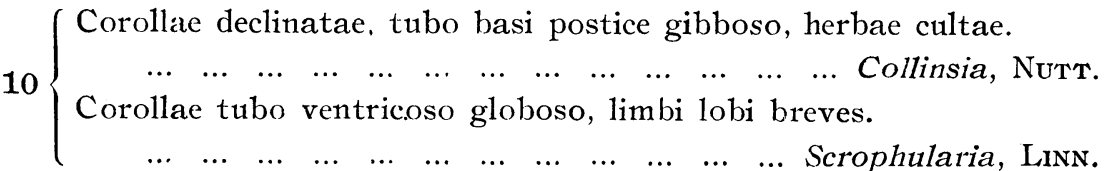

$11\left\{\begin{array}{lllllllllllllllll}\text { Stamina } & 4 & \ldots & \ldots & \ldots & \ldots & \ldots & \ldots & \ldots & \ldots & \ldots & \ldots & \ldots & \ldots & \ldots & \ldots & \ldots 12 \\ \text { Stamina } & 2 & & & \ldots & \ldots & \ldots & \ldots & \ldots & \ldots & \ldots & \ldots & \ldots & \ldots & \ldots & \ldots & \ldots 18\end{array}\right.$

$\begin{array}{llllllllllllllll}\text { Stamina } 2 & . . & \ldots & \ldots & \ldots & \ldots & \ldots & \ldots & \ldots & \ldots & \ldots & \ldots & \ldots & \ldots & \ldots & \ldots 18\end{array}$

$12\left\{\begin{array}{lllllllllll}\text { Stamina omnia tubo inserta } & \ldots & \ldots & \ldots & \ldots & \ldots & \ldots & \ldots & \ldots & \ldots & \ldots 13 \\ \text { Stamina antica ad faucem corollæ } & \text { affixa... } & \ldots & \ldots & \ldots & \ldots & \ldots & \ldots 16\end{array}\right.$

Antherae loculis omnino confluentibus uniloculares, caule stoloni-

$13\left\{\begin{array}{llllllll}\text { forme ad nodos radicante } & \ldots & \ldots & \ldots & \ldots & \ldots & \ldots & \text { Limosella, Linn. }\end{array}\right.$

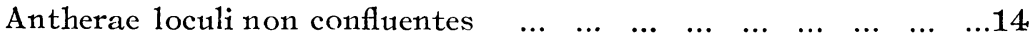

$14\left\{\begin{array}{cccccccccccccc}\text { Antherae biloculares, loculis distinctis. Herbae } & \text { uliginosae. } \\ \ldots & \ldots & \ldots & \ldots & \ldots & \ldots & \ldots & \ldots & \ldots & \ldots & \ldots & \ldots & \ldots & \text { Ambulia, Lam } \\ \text { Antherae biloculares, } & \text { loculis } & \text { contiguis } & \text { sed } & \text { distinctis } & \ldots & \ldots & \ldots & \ldots 15\end{array}\right.$

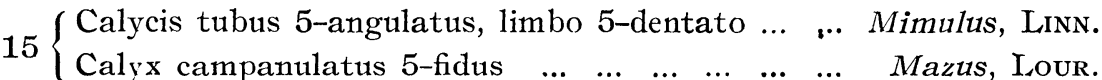

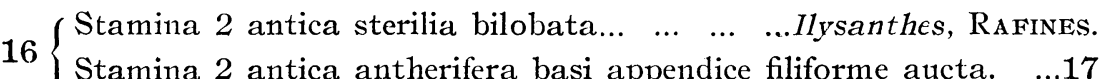

Stamina 2 antica antherifera basi appendice filiforme aucta. $\quad . .17$

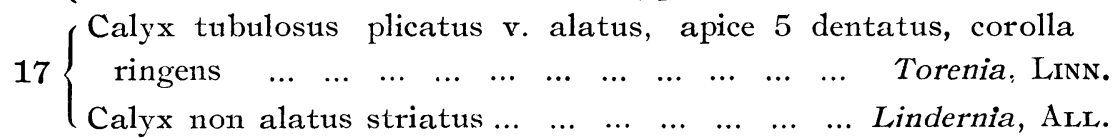

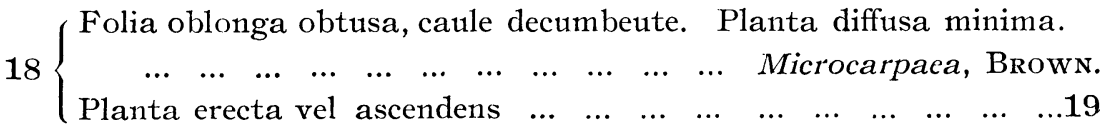

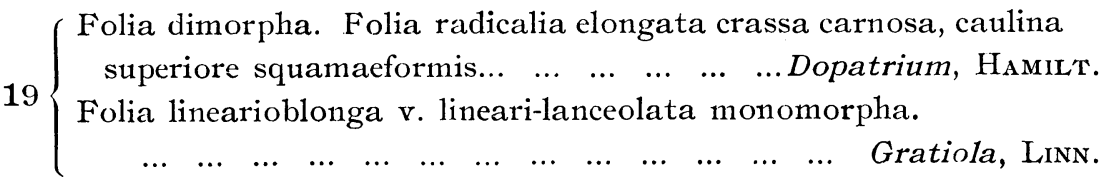

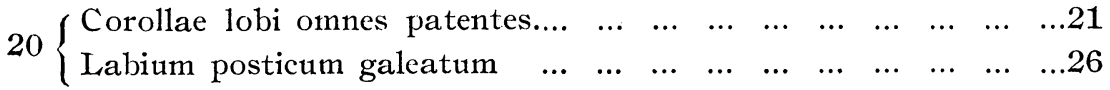

Antherae biloculares sed altero perfecto altero sterile

$21\left\{\begin{array}{rrrrrrrrrrrr}\ldots & \ldots & \ldots & \ldots & \ldots & \ldots & \ldots & \ldots & \ldots & \ldots & \ldots & \text { Centranthera, R. BR. }\end{array}\right.$

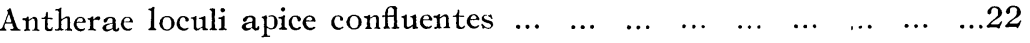

$22\left\{\begin{array}{llllllllll}\text { Corollae tubus brevis } \mathrm{v} \text {. subnullus } & \ldots & \ldots & \ldots & \ldots & \ldots & \ldots & \ldots & \ldots 23\end{array}\right.$

$22\left\{\begin{array}{llllllllllll}\text { Corollae tubus elongatus } & \ldots & \ldots & \ldots & \ldots & \ldots & \ldots & \ldots & \ldots & \ldots & \ldots & \ldots 25\end{array}\right.$ 
$23\left\{\begin{array}{llllllll}\text { Folia opposita } & \text { v. verticillata. } \ldots & \ldots & \ldots & \ldots & \ldots & \ldots & \text { Veronica, Linn. } \\ \text { Folia }\end{array}\right.$

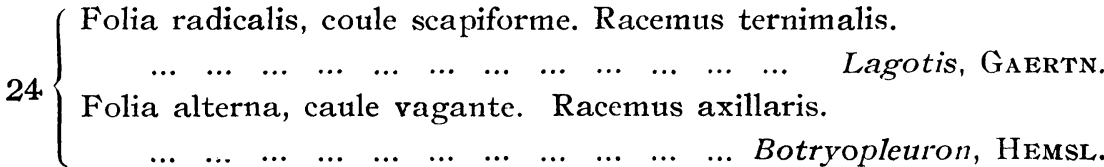

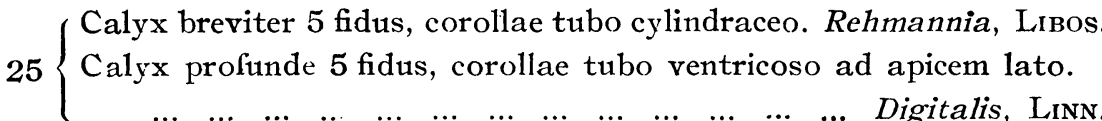
$26\left\{\begin{array}{lllllllllll}\text { Ovula in loculo } 2 . & \ldots & \ldots & \ldots & \ldots & \ldots & \ldots & \ldots & \ldots & \text { Melampyrum, LinN. }\end{array}\right.$ $\left\{\begin{array}{lllllllllll}\text { Ovula in loculo numerosa... } & \ldots & \ldots & \ldots & \ldots & \ldots & \ldots & \ldots & \ldots & \ldots & \ldots 27\end{array}\right.$

$27\left\{\begin{array}{llllllllll}\text { Flores subcalyce non bracteolati. } & \ldots & \ldots & \ldots & \ldots & \ldots & \ldots & \ldots & \ldots & \ldots 28\end{array}\right.$

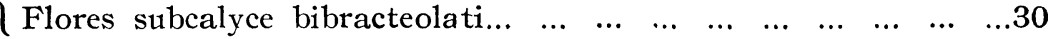
$28\left\{\begin{array}{llllllllll}\text { Galea apice recta. } & \ldots & \ldots & \ldots & \ldots & \ldots & \ldots & \ldots & \ldots & \text { Pedicularis, Linn. }\end{array}\right.$ $\begin{array}{lllllllllllll}\text { Galea apice } \operatorname{reflexa} \ldots & \ldots & \ldots & \ldots & \ldots & \ldots & \ldots & \ldots & \ldots & \ldots & \ldots & \ldots & \ldots 29\end{array}$

29 Semima reticulata, foliis pinnatisectis... Phteirospermum, Bunge.

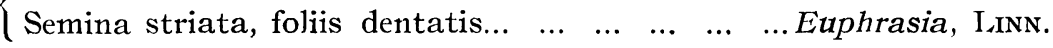
(Folia omnia subconformis, pinnatisecta, calycis tubo elongato

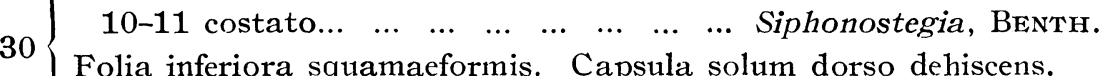
Folia inferiora squamaeformis. Capsula solum dorso dehiscens. $\begin{array}{llllllllllll}\ldots & \ldots & \ldots & \ldots & \ldots & \ldots & \ldots & \ldots & \ldots & \ldots & \ldots & \text { Monochasma, Maxim. }\end{array}$

Verbascum, Linn.

Bentham : DC. Prodr. X 225; Benth. et Hook.: Gene. Pl. II. 928; Wettstein: Eng. u. Pr. Natur. Pfl. IV. 3b. 50.

Verbascum thapsus, ${ }^{1)}$ Linn. Bentham : DC. Prodr. X. 225 ; Wettstein: Eng. u. Pr. Natur. Pfl. IV. 3b. 50 (Fig. 23 A-E); Matsumura: Shokubutsumeikan ${ }^{2)}$ Phan. II. 571.

Nom. Jap. Mozuika. モウズイカ.

Hab. Cult.

Verbascum nigrum, Linn. Bentham: DC, Prodr. X. 238 ; WeTTStein : Eng. u. Pr. Natur. Pfl. IV. 3b. 51 ; Matsumura : 1.c.

Nom. Jap. Kurobana mōzuika. クロバナモウズイカ. Hab. Cult.

Verbascum blattaria, Linn. Bentham : DC. Prodr. X. 230 ; WeTtstein : Eng. u. Pr. Natur. Pfl. IV. 3b. 51; Matsumura: 1.c.

Nom. Jap. Niwatabako ニハタバコ.

Hab. Cult.

1) Plantae quarum nomina literis paullo inclinatis signata sunt introductae.

2) Shokubutsumeikan $=$ Index Plantarum Japonicarun. 


\section{Maurandia, ORT.}

Bentham: DC. Prodr. X. 296; Bentham et Hooker: Gene. Pl. II. 935 ; Wettstein : Eng. u. Pr. Natur. Pfl. IV. 3b. 61.

Maurandia Barclayana, LindL. Bentham: DC. Prodr. X. 297 ; Wettstein: Eng. u. Pr. Natur. Pf. IV. 3b. 61 ; Matsumura : Shokubutsumeikan Phan. II 563.

Nom. Jap.

Hab. Cult.

Maurandia erubescens, Gray. WetTtSTEIN : ENG. u. PR. Natur. Pfl. IV. 3b. 61 ; Matsumura : Shokubutsumeikan Phan. II. 563.

Lophospermum erubescens, Don. Bentham: DC. Prodr. X. 297.

Nom. Jap. Kirikadzura キリカヅラ.

Hab. Cult.

Maurandia scandens, Gray. Wettrstein: Eng. u. Pr. Natur. Pf. IV. 3b. 61 ; Matsumura : Shokubutsumeikan. Phan. II. 563.

Lophospermum scandens, Don., Bentham : DC. Prodr. X 297.

Nom. Jap.

Hab. Cult.

\section{Autirrhinum, Linn.}

Bentham : DC. Prodr. X. 290 ; Benth. et Hook: Gene. P1. II. 934; Wetrstein : Eng. u. Pr. : Nat. Pfl. IV. 3b. 59.

Antirrhinum majus, Linn. Bentham : DC. Prodr. X. 291; MatsuMURA : Shokubutsumeikan Phan. II. 558.

Nom. Jap.

Hab.

\section{Linaria, Juss.}

Bentham: DC. Prodr. X 266 ; Benth et Hook: Gene. Pl.

II. 931 ; Wettstein : Eng. u. Pr. Nat. Pf. IV. 3b. 59.

Clavis Specierum.

$1\left\{\begin{array}{rcccccccccccccc}\text { Suffruticosa, folia } & \text { oblonga integra trinervis glabra. } \\ \ldots & \ldots & \ldots & \ldots & \ldots & \ldots & \ldots & \ldots & \ldots & \ldots & \ldots & \ldots & \text { L. Japonica, MrQ. } \\ \text { Herbae cultae } & \ldots & \ldots & \ldots & \ldots & \ldots & \ldots & \ldots & \ldots & \ldots & \ldots & \ldots & \ldots & \ldots & \ldots\end{array}\right.$

$2\left\{\begin{array}{ccccccccccc}\text { Planta diffusa, rami repentes, foliis cordato-reniformibus } 5-7 \\ \text { lobata... } & \ldots & \ldots & \ldots & \ldots & \ldots & \ldots & \ldots & \ldots & \ldots & \text { L. Cymbalaria, MrLL. }\end{array}\right.$

Planta erecta $\mathrm{v}$. ascendens, foliis linearibus $\mathrm{v}$. linearilanceolatis... 3

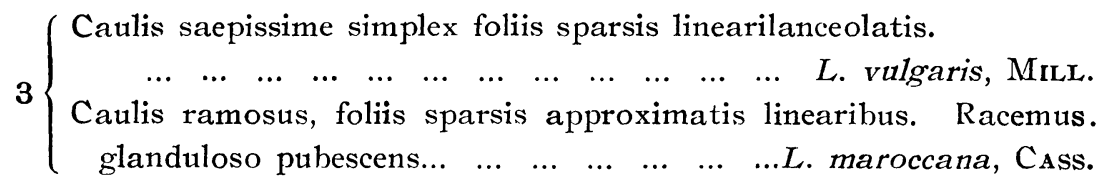


Linaria Japonica, MiQ. Prolusio Fl. Jap. 47; Fr.-SAv. Enum. I. 342; Matsumura : Shokubutsumeikan. Phan. II. 561.

Nom. Jap. Unran ウンラン.

Hab. Hokkaido : Kitami, Woshima ; Honto: Awaji ; Harima ; Izu ; Kadzusa ; Etchu; Ugo.

Linaria cymbalaria, Mrll. Benth: DC. Prodr. X. 266; MatsuMURA ; Shokubutsumeikan. Phan. II. 561.

Nom. Jap. Unrankadzura ウンランカヅラ.

Hab. Cult.

Linaria vulgaris, Bentham: DC. Prodr. X. 273.

Hom. Jap.

Hab. Cult.

Linaria maroccana, Cass. Curtis's Bot. Mag. tab. 5983 ; MatsuMURA: Shokubutsumeikan phan. II 561.

Nom. Jap. Yanagiunran ヤナギウンラン.

Hab. Cult.

\section{Paulownia, SIEB et ZuCC.}

Flora Japonica. I. 25; Bentham: DC. Prodr. X. 300;

Benth. et Hook.: Gene. Pl. II. 939: Wettstein: Eng. u.

Pr. Natur. Pfl. IV. 3b. 66.

Paulownia tomentosa, BAIL.

P. imperialis, S. et Z. Flora Japonica I. 27 t. 10; Fr. et SAv. Enum. I. 342.

Bignonia tomentosa, Thuni : Flora Japonica. 252; Miquel: Prol. 47.

Nom. Jap. Kiri キリ.

Hab. Cult.

\section{Russelia, JACQ.}

Bentham: DC. Prodr. 331; Benth. et Hook: Gene. Pl. II.

940; Wettstein: Eing. u. Pr. Natur. Pf. IV. 3b. 63.

Russelia Juncea, ZuCC. Bentham: DC. Prodr. X. 332; MatsuMURA: Shokubutsumeikan Phan: II. 568.

Nom. Jap. Hanachōji ハナテウジ.

Hab. Cult.

Pentstemon, Miтch.

Bentham: DC. Prodr. X. 320; Benth. et Hook: Gene. P1. II. 940; Wettstein: Eng. u. Pr. Nat. Pfl. IV. 3b. 65 
1. Frutices humiles, foliis ovatis obtuse serrata, brevissime $\begin{array}{lllllllllll}\text { petiolatis } & \ldots & \ldots & \ldots & \ldots & \ldots & \ldots & \ldots & \ldots & \ldots & \text { P. frutescens, LamB. }\end{array}$

2. Herba alta, foliis sessilibus acute lanceolatis denticulatis. Iuflorescentia elongata paniculata ... P. campanulata, WiLLd.

Pentstemon frutescens, Lamb. Bentham: DC. Prodr. X. 321 ;

Ledeb: F1. Ros. III. 221; Matsumura: Shokubutsumeikan phan. II 568.

Nom. Jap. Iwabukuro イハブクロ.

Hab. Honto: Rikuchū; Uzen; Ugo; Mutsu; Yezo; Woshima; Ishikari.

Pentstemon campanulatus, Willd. Bentham : DC. Prodr. X. 326.

Nom. Jap. Tsuriganeyanagiツリガネヤナギ.

Hab. Cult.

Collinsia, Nutr.

Bentham ; DC. Prodr. X. 317 ; Benth. et Hookm : Gene. Pl. II. 941; Wettstein: Eng. u. Pr. Natur. Pfl. IV. 3b. 64.

Collinsia bicolor, Benth. Bentham: DC. Prodr. X. 318; MatsuMURA: Shokubutsumeikan. Phan. II. 559.

Nom. Jap.

Hab. Cult.

Collinsia verna, Nutt.Bentham: DC. Prodr. X. 318; Matsumura: 1.c.

Nom. Jap.

Hab. Cult.

\section{Scrophularia, LinN.}

Bentham: DC. Prodr. X. 302 ; Benth. et Hook.

Gene. P1. 938; Wettstein: Eng. u. Pr. Natur. Pfl. IV. 3b. 65.

Clavis specierum.

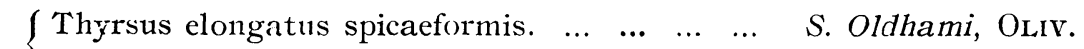

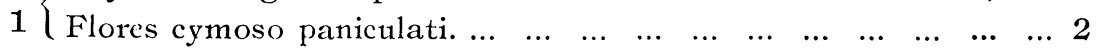

Cymulus laxissimus pedicellis pedunculisque elongatis filiformibus.

$\begin{array}{llllllllllllll}\text { Caulis non alatus } & \ldots & \ldots & \ldots & \ldots & \ldots & \ldots & \ldots & \ldots & \ldots & \ldots & \ldots & \ldots & 3\end{array}$

2 Cymulus densiusculus, pedicellis pedunculisque validiusculis.

$\begin{array}{llllllllllllllll}\text { Caulis alatus } & \ldots & \ldots & \ldots & \ldots & \ldots & \ldots & \ldots & \ldots & \ldots & \ldots & \ldots & \ldots & \ldots & \ldots & 4\end{array}$

$3\left\{\begin{array}{lllllll}\text { Inflorescentia efoliata. ... } & \ldots & \ldots & \ldots & \text { S. duplicato-sertata, Makino. }\end{array}\right.$

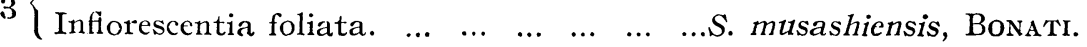

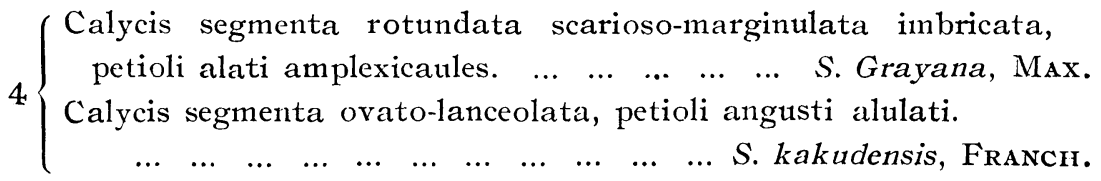


Scrophularia Oldhami, Olrv. in Jour. Linn. Soc. IX. 167; MAKINo: T.B.M. XII. 226 ; Matsumura: Shokubutsumeikan. Phan. II. 569 ; NaKaI: Flor. Kor. II. 118 ; Stiefelhagen: Engl. Bot. Jahrb. XLIV, (1910). 462.

S. Buergerina MiQ.: Prol. 48.

S. Oldhami var. distantifolia Mro. 1.c. 47; FR. et. SAv. Enum. I. 343.

Nom. Jap. Gomanoha gusa ゴマノハグサ.

Hab. Honto: Suoh; Musashi; Iwashiro; Kyūshã: Higo.

Scrophularia duplicato-serrata, (MiQ.) Makino: T. B. M. XX. 4; Mastumura: Shokubutsumeikan. Phan. II. 569.

S. alata var. duplicato-serrata, MiQ.: Prol. 47; Franch. Sav.: Enum. I 343; Hayata: Fl. Mon. For. 172.

Nom. Jap. Hina no Usutsubo ヒナノウスツボ.

Hab. Honto: Kawachi; Shikoku: Awa; Iyo; Tosa.

Scrophularia musashiensis, Bonati: Bull. Soc. Bot. (1911). 520.

Nom. Jap. Satsuki hina no usutsubo サッヒキナノウスッボ.

Hab. Musashi: Mitake; Mt. Takao.

Scrophularia Grayana, Maxim. Komarov: Fl. Mansh. III. 416; STIEFELHAGEN: 1.c. 468.

Scrophularia alata, A. Gray : On the Bot. of Jap. 401; Miquel: Prol. 47: Fr. Sav. I. 342; Makino: T. B. M. XII. 226; Matsumura: Shokubutsumeikan, Phan. II. 569 ; Fr. Schmidt: Reis. Amur. Sach. 162.

Nom. Jap. Yezo hinano usutsubo エゾヒナノウスツボ.

Hab. Yezo; Kuril.

Scrophularia kakudeusis, Franch. Makino: T. B. M. XII. 226; MATsumura : Shokubutsumeikan: phan. II. 569.

S. nodosa (non L.) Stiefelmhagen 1. c. 461; Matsuda: T. B. M. XXVIII. 38.

Nom. Jap. Ohina no usutsubo オホヒナノウスツボ.

Hab. Shikoku: Tosa; Honto: Shinano; Musashi.

\section{Limosella, Linn.}

Bentham: DC. Prodr. X. 426; Benth. et Hook.

Gene. P1. II. 958; Wettstein: Eng. u. Pr. Natur. Pfl. IV.

3b. 78 .

Limosella aquatica, Linn. Bentham: DC. Prodr. X, 426; Ledeb.: F1. Ros. III. 226; Yabe et Yendo: T. B. M. XVIII. 194; Matsumura: Shokubutsumeikan. Phan. II. 561; Hooker: F1. Brit. Ind. IV. 288; Wettstein: Eing. u. Pr.: Natur. pfl. IV. 3b. 78. 
Nom. Jap. Kitami-so キターサウ.

Hab. Simshu; Kitami.

\section{Ambulia, LAM.}

Wettstein: Eng. u. Pr. Natur. pfl. IV. 3b. 73.

Limnophylla, Benth. DC. Prodr. X. 386 ; Benth. et Hook.: Gen. P1. II. 950.

\section{Clavis Specierum.}

1. Folia oblonga ternato-verticillata v. opposita obtuse serrata,

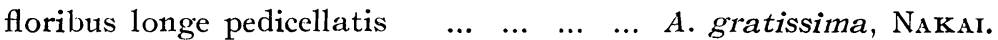

2. Folia 7-10 verticillata pinnatisecta, segmentis linearibus, subramea capilloso ramossisimis, floribus sessilibus

$$
\begin{array}{llllllllllll}
\ldots & \ldots & \ldots & \ldots & \ldots & \ldots & \ldots & \ldots & \ldots & \ldots & \ldots & \text { A. sessiliflora, BAllL. }
\end{array}
$$

Ambulia gratissima, NAKAI.

Lymnophylla gratissima, BL. Hooker: F1. Brit. Ind. IV. 268.

Nom. Jap. Shisokusa シソクサ.

Hab. Honto: Aki; Musashi; Kadzusa; Shikoku: Tosa.

Ambulia sessiliflola, Baill. Wettstein: Eng. u. Pr. Natur. Pfl. IV. 3b. 73; Matsumura: Shokubutsumeikan. Phan. II. 558; Nakar: Fl. Kor. II. 120.

Lymnophylla sessiliflora, BL. Bentham : DC. Prodr. X. 389; Hooker; F1. Brit. Ind. IV. 270 ; Mrquel: Prol. 49 ; Maximowicz: Mel. Bio. IX. 407.

Nom. Jap. Kikumo キクモ.

Hab. Honto: Stıo; Aki; Ise; Tōtōmi; Musashi; Shimoosa; Iwashiro; Uzen ; Kyūshū: Hyūga.

\section{Mimulus, Liм.}

Bentham: DC. Prodr. X. 368; Benth. et Hook: Gene. P1. II. 946; Wettstein: Eng. u. Pr. Natur. Pf. IV. 3b. 71.

\section{Clavis Specierum.}

1. Folia sessilis et amplexicaulis, pedicellis foliis duplobrevioribus.

2. Folia petiolata.

a. Herba diffusa decumbens glabra. Folia ovata 4-5 crenato-

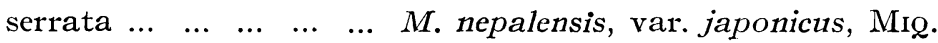

b. Herba ascendens v. suberecta, caule cum ramis foliisque pubescente. foliis oblongis obtuse serratis. M.moschatus Don. 
Mimulus sessilifolius, Max. in Mel. Bio. IX. 401; Matsumura: Shokubutsumcikan. Phan. II. 565. Franch. SAv. Enum. II 456.

Nom. Jap. Oba mizohozuki オホバミゾハウジキ.

Hab. Honto: Kaga; Shinano; Shimodzuke; Iwagi; Iwashiro; Uzen; Ugo; Mutsu; Yezo: Ishikari.

Mimulus nepalensis, Benth. var. japonius, Mro. in Prol. 48; Maximowicz: Mel. Bio. IX. 401; Fret. Sav. Enum. II. 455; MatsuMURA: Shokubutsumeikan. Phan. II 564.

Mimulus nepalensis, Benth. Hooker: Fl. Brit. Ind. IV. 258; Franch. Sav. I. 343.

Torenia inflata, MiQ. Prol. 356; Franch. Sav.: Enum. I. 345.

Nom. Jap. Mizohozuki ミゾホ、ヅキ.

Hab. Honto; Shikoku; Kyūshū; Yezo.

Minlus moschotus, Don. Bentham: DC. Prodr. X. 372; WetTstein: Eng. u. Pr. Natur. Pf. IV. 3b. 72; Matsumura: Shokubutsumeikan. Phan. II. 565 .

Nom. Jap. Nioi mizohozuki ニホヒiゾホ、ヅキ.

Hab. Cult.

\section{Mazus, Lour.}

Bentham: DC. Prodr. X. 375; Benth. et Hook: Gene. P1. II. 947; Wettstein: Eng. u. Pr. Natur. Pfl. IV. 3b. 72.

Clavis Specierum.

1. Annuae non stoloniferae erectae, floribus $1 \mathrm{~cm}$. longis \begin{tabular}{lllllllllll}
$\ldots$ & $\ldots$ & $\ldots$ & $\ldots$ & $\ldots$ & $\ldots$ & $\ldots$ & $\ldots$ & $\ldots$ & $\ldots$ & $\ldots$ \\
\hline
\end{tabular}

2. Perennes stoloniferae, caule decumbente v. ascendente.

a. Caulis ascendens v. erectus, foliis retundatis grosse dentatis, corollae tubo brevi, labio postico obovato leviter bifido

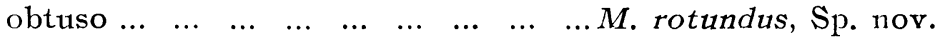

b. Folia ovata v. obovata crenato-serrata v. incisa, labio superiore ovato acutinsculo leviter bifido acuto.

M. stolonifer, Makino.

. Flores albi ... ... M. stolonifer form. Albiflora, Makino.

B. Caulis erectus v. ascendens $5 \mathrm{~cm}$. altus foliis densissime obtectus, floribus minoribus.

M. stolonifer var. contractus. Makino.

Mazus japohicus, O. Kcz. in Rev. Gen. Pl. II. 462 ; Makino: T. B. M. XVI. 170 ; Matsumura: Shokubutsumeikan. Phan. II. 563.

Lindernia japonica, Thunв. Fl. Jap. 253. 
Mazus rugosus, Lour. Maximowicz: Mel. Bio. IX. 402 ; MrQuel: Prol. 48 ; Fr. et SAv.: Enum. I. 344; Makino: T. B. M. XI. 391 ; Matsum. et Hay.: Enum. Form. 275; Hayata: Fl. Mont. Form. 173.

Nom. Jap. Tokiwahaze トキハハゼ.

Hab. Honto; Shikoku ; Kyushü ; Yezo.

Mazus rotundus, Sp. nov.

Caulis ascendens $v$. erectus simplex v. basi ramosus pilosus $10-15 \mathrm{~cm}$ altus, foliis oppositis $\mathrm{v}$. alternis inferibus longe petiolatis, petiolis alatis ad apicem decrescentibus, laminis ovatis oblongis $v$. rotundatis grosse dentatis, basi profunde incisis, dentibus utrinque $5-6$ obtusis $1 \frac{1}{2}-2 \mathrm{~cm}$. longis $1-1 / 2 \mathrm{~cm}$. latis, foliis superioribus breviter petiolatis, petiolis alatis decurrentibus 5-12 mm. longis, lanimis rotundatis basi cuneatis grosse crenatis, crenis obtusis rotundatis, $1-2 \mathrm{~cm}$. longis et latis, foliis omnibus crassinsculis carnosulis. Racemi axillares v. terminales laxi, floribus longe pedicellatis, pedicellis pilosis $1-2 \mathrm{~cm}$ longis. Calyx late campanulatus profunde 5-fidus, laciniis ovatis acutis $8 \mathrm{~mm}$. longis, corolla $11 / 2 \mathrm{~cm}$. longa, tubo calyce multo breviore $6 \mathrm{~mm}$. longo, labio postico ambitu obovato $7 \mathrm{~mm}$. longo, apice leviter bilobato, lobis rotundatis, labio antico postico triplo majore trilobato $11 \mathrm{~mm}$. longo, lobis lateralibus medio dupromajoribus, omnibus rotundatis paulo cmarginatis. Stamina 4 fertilia didynama, antherarum loculis divaricatis, filamentis filiformibus 5-6 mm. longis glabris, stylo $10-12 \mathrm{~mm}$. longo, apice bilamellato, lamellis obovatis aequalibus intus stigmatosis. Ovario globoso biloculo, ovulis numerosis. Capsula ignota.

Hom. Jap. Maruba sagigoke マルバサギコケ.

Hab. Suoh. Planta endemica.

Mazus stolonifer, MaKino.: in List of seeds Bot. Gard. Imp. Univ. Tokyo (1896) p. 17. Invma Yokusar: Somokudzusetsu (MaK. Rev.) Vol. XI. pl. 69 ;

Vandellia Japonica, MIQ: Prol. 50; Fr. SAv.: Enum. I 346.

Mazus Japonicus, MAK.: T. B. M. XI. 391 (non O. Kcz.).

M. rugosus var. Stolonifer, MAx.: Mel. Biol. IX. 403.

M. rugosus var. Macranthus, Fr. et. Sav. Enum. I 344.

M. rugosus var. rotundifolia, FR. et. Sav.: 1.c.

M. Miqueli, Makino: T. B. M. XVI (1902). 162; Matsumura: Shokubutsumeikan. Phan. II. 563. 
Mazus japonicus, Bonati in Bull. Herb. Bois. (1908) 536.

Nom. Jap. Sagigoke サギコケ.

Hab. Honto; Shikoku ; Kyūshù ; Yezo.

forma albiflora (MaK.) : T. B. M. XVI. 162; Matsumura: Shokubutsumeikan Phan. II. 563.

M. Japonicus var. albiflorus, Mak.: T. B. M. XV. 96.

M. Miqaeli from albiftora Mak. T. B. M. XVI. 162.

Nom. Jap. Sagishiba サギシバ.

Hab. Sagami; Musashi; Awa:

var. contractus (MAK.). T. B. M. XVI. 162; MATsumura; Shokubutsumeikan Phan. II. 563.

M. Miqueli var: contractus Mak. T. B. M. XVI. 162.

Nom. Jap. Jakagoso ジヤカゴサウ.

Hab. Tōkyō.

Species Japonicae non vidi.

Mazus Englerianus, Bonati in Bull. Herb. Bois. (1908.) 536.

Hab. Hizen: Gotōo.

\section{Ilysanthes, RAFIN.}

Bentham: DC. Prodr, X. 418; Benth. et Hook.: Gene.

Pl. II. 955 ; Wettstein: Eng. u. Pr. Natur. Pfl. IV. 3b. 79.

Ilysanthes veronicifolia, URB. H. Hattori: Pfl. Bon. 34; MAtsuMURA: Shokubutsumeikan. Phan. II. 561.

Bonuaya veronicifolia, Spr. Maxımowicz: Mel. Bio. IX. 421; Matsum. et Hay.: Enum. For. 281; Hayata: Fl. Mont. For. 173.

B. veronicifolia var. verbenaefolıa, Hook. Makıno: Nippon Shokubutsushi-zuhen VII. P1. 44.

Nom. Jap. Suzume no togarashi ス・゙メノタウガラシ.

Hab. Honto: Suoh; Shikoku: Sanuki; Ogasawarajima (Bonin).

\section{Torenia, LinN}

Bentham: DC. prodr. X. 409; Benth. et Hook.: Gen. Pl.

II. 954; Wettstein: Eng. u. Pr. Natur. Pfl. IV. 3b. 79.

Clavis specierum.

1. Calyx profunde 5 fidus. Planta erecta v. ascendens gracilis, $\begin{array}{lllllllllll}\text { setulosa } & \ldots & \ldots & \ldots & \ldots & \ldots & \ldots & \ldots & \ldots & \ldots & \text { T. setulosa, Maxim. }\end{array}$

2. Calyx tubulosus apice $\mathbf{5}$ dentatus.

a. Planta diffusa caule decumbente trichotome, foliis ovatis serratis 8-12 mm. longa ... T. crustacea, Cham. et ScHL. 
b. Planta erecta, calycis tubo 5 angulato. angulis alatis. Corolla dorso $3 \frac{1}{2} \mathrm{~cm}$. longa, folia $3-4 \mathrm{~cm}$. longa.

Torenia setulosa, ${ }^{\prime}$ Maxim. in Mel. Bio. XII. 500 ; Matsumura: Shokubutsumeikan. Phan. II. 570.

Nom. Jap. Shisoba Urikusa シソバウリクサ.

Hab. Kii.

Torenia crustacea, Cham. et Schl. Makino: T. B. M. XI. 390; Matsumura: Shokubutsumeikan. Phan. II. 570.

Vandellia crustacea, Benth.: Flora Hongk. 250; Hooker: Fl. Brit. Ind. IV. 279 ; Maximowicz: Mel. Bio. IX 412; Miguel : Prol. 360 ; Franch. Sav.: Enum. I. 345; Hattori: Pf. Bon. 34; Matsum. et HAy.: Enum. Form. 279; YABE: T. B. M. XVIII 55.

Nom. Jap. Urikusa ウリクサ.

Hab. Honto ; Shikoku ; Kyūshū ; Yezo.

Torenia Fournieri, Lind.

Nom. Jap. Hana urikusa ハナウリクサ.

Hab. Cult.

\section{Lindernia, ALL.}

Wererstein: Eng. 1. P. Natur. Pfl. IV. 3b. 79.

Vandellia, Linn; Bentrham: DC. Prodr. X. 562.

\section{Clavis specierum.}

1. Folia anguste oblonga $v$. linearis obtuse serrata, capsula lineare acuminata, calyce 2-3 plo longiore. ... L. angustifolia, Wer'rs.

2. Folia ovato-oblonga obtusa integra 3-nervia, capsula calycem subaequans oblonga obtusa ...

Lindernia angustifolia, Wetrs. Hatroni: Pfl. Bon. 34; MA'sumura: Shokubutsumeikan. Phan. II 561; Wetrstern: Eng. u. I'. Natur. IV. 3b. 79.

Vandellia augustifolia, Benth. Maxımowicz: Mel. Bio. IX. 413 ; Makino: Nippon Shokubutsushi-dzuhen pl. 32; Benteram: DC. prod. X. 417; Hooker: Fl. Brit. Ind. IV. 282.

Nom. Jap. Aze togarashi アゼタウガラシ.

Hab. Musashi; Sagami; Suoh; Bonin.

Lindernia pyxidaria, Alı. Bentham: DC. Prodr. X. 418; MatsuMURA : Shokubutsumeikan. Phan. II. 562; Wettstein: Eng. u. P. Natur. Pfl. IV. 3b. 80 ; NAKAI; Flo. Kor. II. 120. 
Vandellia pyxidaria, MAx. Makino: T. B. M.

Vandellia erecta, Benth. Maximowicz: Mel. Bio. IX. 413 ; Benтham: DC. Prodr. X. 415; Hooker: Fl. Brit. Ind. IV. 281; Matsum. et Hay.: Enum. Form. 280.

Nom. Jap. Azena アゼナ.

Hab. Honto: Suoh; Tōtōmi; Musashi ; Kadzusa ; Hitachi. Shikoku: Awa. Kyüshü: Chikuzen; Bungo.

\section{Microcarpaed, R. BR.}

Bentham: DC. Prodr. X. 433; Benth. et Hook.: Gen. Pl.

II. 957 ; Wettstein: Eng. u. Pr. Natur. Pfl. IV. 3b. 77.

Microcarpaea muscosa, R. BR. Bentham: DC. Prodr. X. 433; Hooker: Fl. Brit. Ind. IV. 287; Makino: Nippon Shokubutsushidzuhen pl. 9; Matsumura: Shokubutsumeikan. Phan. II. 565; NakaI: Fl. Kor. II. 121; Wettstein: Eng. u. Pr. IV. 3b. 77.

Nom. Jap. Suzume no hakobe ス・゙メノハコベ.

Hab. Shimoosa.

\section{Dopatrium, Намilt.}

Bentham: DC. Prodr. X. 407; Benth. et Hook.: Gene. Pl.

II. 653; Wettstein: Eng. u. Pr. Natur. Pfl. IV. 3b. 75.

Dopatrium junceum, Hamilt. Maximowicz: Mel. Bio. IX. 409 654; Fr. SAv. Enum. II. 457; YABE: T. B. M. XVIII. 55; Mássumet Hayata: Enum. Form. 284; Nakai: Fl. Kor. II. 119; Hooker: Fl. Brit. Ind. IV. 273 ; Bentham : Fl. Hongk. 249 ; DC. Prodr. X. 407 ; Matsumura: Shokubutsumeikan. Phan. II. 559.

D. Japonicum, Fr. et Sav.: Enum. I. 345.

Nom. Jap. Abu no me アブノメ.

Hab. Honto: Suoh; Iwashiro; Uzen ; Shikoku: Tosa ; Ky $\bar{u}-$ shū : Tsushima.

\section{Gratiola, Linn.}

Bentham : DC. Prodr. X. 402 ; Benth. et Hook.: Genc. P1. II. 953; Wet'stein: Eng. u. Pr. Natur. Pfl. IV. 3b. 75.

Clavis Specierum.

1. Flores sessiles, capsula calycem aequilonga globosa 4-5 mm. longa. Folia lineari-oblonga $2 \frac{1}{2} \mathrm{~cm}$. longa et 5-7 mm. lata tri$\begin{array}{lllllllllllll}\text { nervis } & \ldots & \ldots & \ldots & \ldots & \ldots & \ldots & \ldots & \ldots & \ldots & \ldots & \ldots & \text { G. japonica, MiQ. }\end{array}$ 
2. Flores pedicellati.

a. Folia oblonga, ovata, v. elliptica ...G. adenocaula, Maxım.

b. Folia lineari-lanceolata angustissima integra 6-10 $\mathrm{mm}$. longa. Capsula ovata acuta, Calycis laciniis breviora.

G. Violacea, Maxim.

a. Humilis a basi ramosa $2-3 \mathrm{~cm}$. alta. Folia linearis setacea. Hab. Nikkō

... $\quad \ldots . . . . . G$. Violacea. var. saginoides, Fr. et SAV.

Gratiola japonica, MiQ.: Prol. 49; Fr. et SAv. Enum. I. 345; Maximowicz: Mel. Bio. IX. 407; XII. 764; Matsumura: Shokubutsumeikan. Phan. II. 560.

G. micrantha Fr. et SAv.: Enum. II. 456.

Nom. Jap. Oabu no me オホアブノメ.

Hab. Bitchū; Musashi; Iwashiro.

Gratiola adenccaula, Maxim. in Mel. Bio. XII. 765; Matsumura : Shokubutsumeikan. Phan. II. 560.

Nom. Jap. Maruba no sawatogarashi マルパノサハタガラシ.

Hab. Kadzusa.

Gratiola violacea, Maxim. in Mel. Bio. IX. 407; XII. 764; Fr. et Sav. Enum. II. 456 ; Matsumura: Shokubutsumeikan. Phan. II. 560 ; NAKAI: Fl. Kor. II. 120.

Nom. Jap. Sawatogarashi サハタウガラシ.

Hab. Honto: Kadzusa ; Shimoosa; Mutsu ; Kyūshū : Hizen ; Buzen.

var. Saginoides, Fr. et SAn.: Enum. II. 456.

G. saginoides, (F. S.). MATsumura: Shokubutsumeikan Phan. II. 560 ; Ilysanthes saginoides, Fr. et SAv. I. 346.

Nom. Jap. Akanumasö アカヌマサウ.

Hab. Nikk̄̄.

\section{Centranthera, $\mathrm{R}$. BR.}

Bentham: DC. Prodr. X. 525; Benth. et Hook. : Gen. Pl.

II. 969 ; Wettstein : Eng. u. Pr. Natur. PH. IV. 3b. 94.

Contranthera brunoniana, Wall. Bentham: DC. Prodr. X. 525; Hooker: Fl. Brit. Ind. IV. 301; Matsumura: Shokubutumeikan Phan. II. 559.

C. hispida, R. Br. Mrquel: Prol. 52; Fr. et SAv. I. 350:

Nom. Jap. Gomakusa ゴマクサ.

Hab. Honto: Kadzusa; Shikoku: Tosa; Kyūshū: Osumi; Satzuma. 


\section{Veronica, Linn.}

Bentham: DC. Prodr. X. 458; Benth. et Hook: Gene. Pl.

II. 964; Wettstein: Eng. u. Pr. Natur. Pfl. IV. 3 h. 85.

\section{Clavis specierum.}

$1\left\{\begin{array}{lllllllllll}\text { Racemi v. Spicac terminales. } & \ldots & \ldots & \ldots & \ldots & \ldots & \ldots & \ldots & \ldots & \ldots & \ldots \\ \text { Racemi v. spicae axillares } \ldots & \ldots & \ldots & \ldots & \ldots & \ldots & \ldots & \ldots & \ldots & \ldots & \ldots 19\end{array}\right.$

( Folia verticillata, calyce parvo $4-5$ partito, corollae tubo limbo sto et calyce multo longiore, capsula ovata

$\begin{array}{llllllllllllllll}\text { Folia } 0 p p o s i t a & \ldots & \ldots & \ldots & \ldots & \ldots & \ldots & \ldots & \ldots & \ldots & \ldots & \ldots & \ldots & \ldots & \ldots & 4\end{array}$

(Folia 6-9 verticillata, floribus subsessilibus... $\ldots$.. V. sibirica, L.

3 Folia 4-6 verticillata, pedicellis brevissimis $v$. bracteas subae-

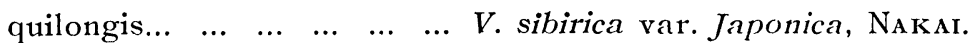

$4\left\{\begin{array}{l}\text { Folia floralia alterna, caulinis subconformis. } \\ \text {. }\end{array}\right.$

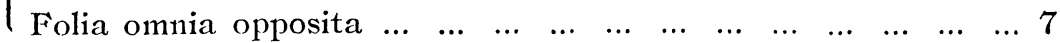

Folia 3-5lo bata brevissime petiolata, calycis segmentis ovato-

$5\left\{\begin{array}{llllllllllll}\text { oblongi i } & \ldots & \ldots & \ldots & \ldots & \ldots & \ldots & \ldots & \ldots & \ldots & \ldots & V \text {. triphvllos, Linn. }\end{array}\right.$

$\begin{array}{llllllllllllll}\text { Folia orbiculata } \mathrm{v} \text {. ovata } & \ldots & \ldots & \ldots & \ldots & \ldots & \ldots & \ldots & \ldots & \ldots & \ldots & \ldots & 6\end{array}$

(Folia ovata utrinque 5-6 dentata vulgo $1-1 \frac{1}{2} \mathrm{~cm}$. longa. Pedicelli in axillis solitarii foliis multo longiores. Capsula compressa

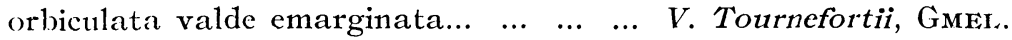

6 Folia suborbiculata utrinque vulgo 4 dentata 5-7 $\mathrm{mm}$. longa, calycis segmentis foliaccis ovato acutis. pedicellis foliis paulo longioribus. Capsula late orbiculata cmarginata, lobis rotundatis sinu acute separatus $\ldots \begin{array}{ccccccc}\ldots & \ldots & \ldots & \ldots & \ldots & \ldots & \ldots\end{array}$

(Corollae tubus latitudine sua longiore, calycem V. limbum suum excedens v. iis brevior. ... $\ldots$... Sectio Pseudolysimachina ... $\quad \ldots 8$

Corollae tubus brevissimus v. absit, bractea inferiora foliis cau-

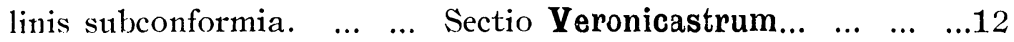

Bracteae flores superanti, calycis laciniis obtusis. Planta canopubescentibus dense obtecta, foliis oblanceolatis v. oblongolan$\begin{array}{lllllllllllll}\text { ceolatis. } & \ldots & \ldots & \ldots & \ldots & \ldots & \ldots & \ldots & \ldots & \ldots & \ldots & \ldots & V \text {. incana, Linn. }\end{array}$

$\begin{array}{llllll}\text { Bracteae flores non excedenti calycis laciniis acutis } & \ldots & \ldots & \ldots & \ldots & 9\end{array}$

Folia crassa glabra oblonga obtuse serrata v. subintegra racemo

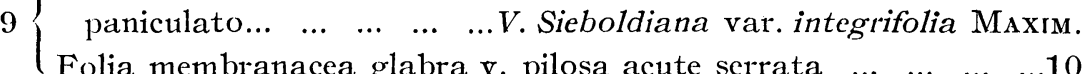

$\begin{array}{lllllll}\text { Folia membranacea glabra } \nabla \text {. pilosa acute serrata } & \ldots & \ldots & \ldots & \ldots & \ldots & \end{array}$

$10\left\{\begin{array}{llllllllllllll}\text { Folia petiolata } \ldots & \ldots & \ldots & \ldots & \ldots & \ldots & \ldots & \ldots & \ldots & \ldots & \ldots & \ldots & \ldots & \ldots \\ \text { Folia brevissime petiolata } & \text { v. sessilis } & \text { racemo } & \text { elongato densifloro...12 }\end{array}\right.$ 
Folia deltoideo -ovata $v$. ovata basi rotundata $\nabla$. truncata cuneatave. Hab. Higo ... Folia ovata $\mathrm{v}$. oblonga acuminata, basi cordata truncata $\mathrm{v}$. rotundata subduplicatoserrata, racemo densi-floro pedicellis bracteis longioribus $\mathrm{v}$. rarissime brevioribus. $V$. longifolia. LinN. a. Folia oblonga acuminata basi cordata v. rotundata plus minus obliqua glabra v. pilosiuscula pedicellis bracteis $\begin{array}{lllllllllll}\text { longioribus. } & \ldots & \ldots & \ldots & \ldots & \ldots & \ldots & \ldots & \ldots & \ldots & \text { Var. } \alpha \text {. typica. }\end{array}$

1). Folia oblonga acuminata basi cordata supra glabra subtus cano-pubescens, calycis laciniis bracteis subaequalibus pedicellis longioribus ... c. Folia elongata lanceolata basi cordata v. truncata, longitudo latitudine 4-5 plo longiora, supraet subtus densissime cano-pubescentibus obtecta, margíne dense serrulata

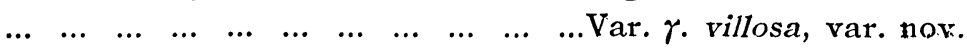

Folia sessilis $\mathbf{v}$. bressime petiolata amplexicaulis ovata acuta argute serrata in nervis sparse pilosa, racemo simplice v. ternato, calycis segmentis ovatis margine pilosa, capsula orbicu-

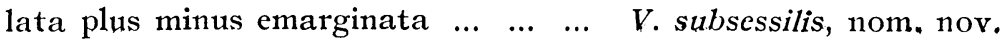
Folia lanceolata v. oblanceolata crenato serrata glabra v. in nervis sparse pilosa, racemo solitario $\mathrm{v}$. ternoto elongato, 12 calycis laciniis linearibus margine pilosis, capsula orbiculata $\begin{array}{llllllllll}\text { obtusa emarginata } & \ldots & \ldots & \ldots & \ldots & \ldots & \ldots & \ldots & \ldots & V \text {. spuria, Linn. }\end{array}$ a. Folia plerumque lato-lanceolata, racemis saepissime ternatis subpaniculatis bracteis pedicellis brevioribus v. subaequalibus. ...

b. Folia anguste oblanceolata, bracteis inferioribus pedicellis $\begin{array}{llllllllll}\text { longioribus } & \ldots & \ldots & \ldots & \ldots & \ldots & \ldots & \ldots & \beta & \text {. angustifolia, BENTH. }\end{array}$

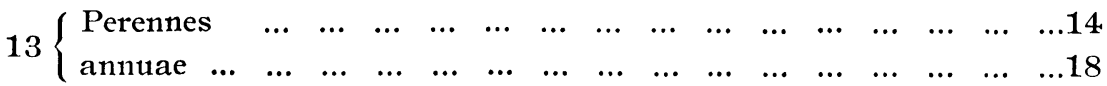

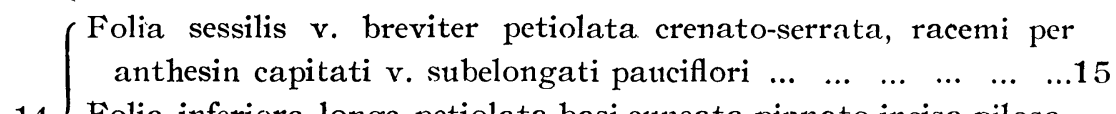

14. Folia inferiora longe petiolata hasi cuneata pinnato incisa pilosa, racemi per anthesin breves pluríflori, fructiferi elongati laxi

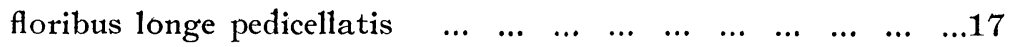

Planta diffusa ad basin ramosa, caule rasmisque repenti foliis brevissime petiolatis oblongis ovatis v. ellipticis obtusissimis,

$15\left\{\begin{array}{lllllllll}\text { obtuse crenatis } & \ldots & \ldots & \ldots & \ldots & \ldots & \ldots & \ldots & \ldots\end{array}\right.$

Planta humilis erecta saepissime simplex, foliis ovatis v. oblongis $\begin{array}{llllllllllll}\text { obtusis argute serratis. } & \ldots & \ldots & \ldots & \ldots & \ldots & \ldots & \ldots & \ldots & \ldots & \ldots & \ldots 16\end{array}$ 


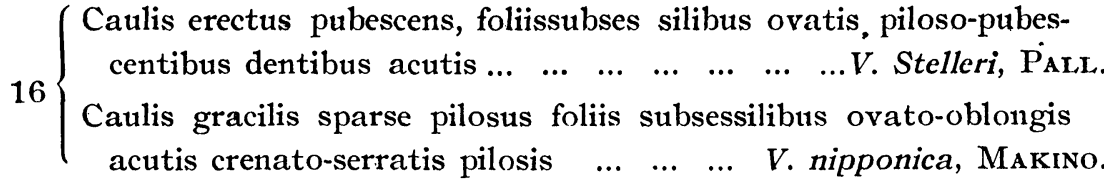

(Folia glabra ovato lanceolata subpinnatifida obtusa, calycis laciniis oblongis pilosiusculis. Capsula oblonga emarginata.

17 Folia obovata v. ovato-oblonga, basi cuneata, sparse pilosa incisodentata, dentibus apice 2-3 denticulatis acutis, racemo elongato laxo pedicellis calyce 2-3 plo longioribus. Capsula compressa obovata valide emarginata ... ...V. senanensis, Maxim.

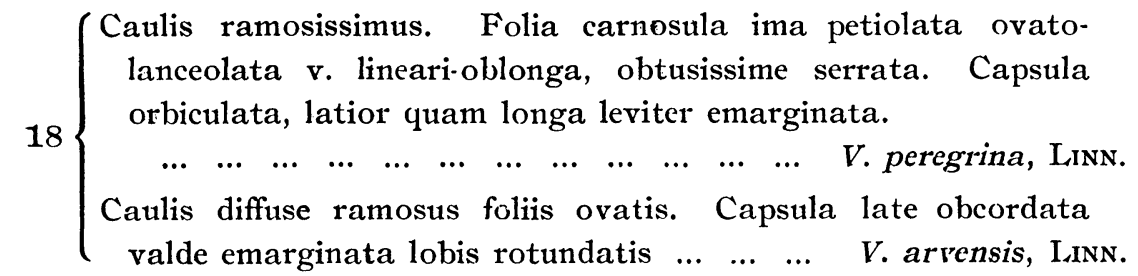

(Racemi oppositi elongati. Capsula a latere compressa emarginata, valvulis demum bipartitis una v. utraque a columma

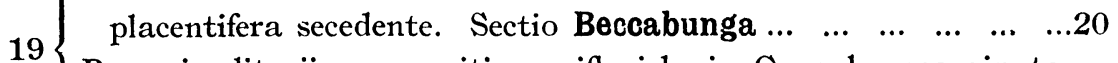

Racemi solitarii v. oppositi pauciflori laxi. Capsula emarginata, $\begin{array}{llllll}\text { valulis columnae placentiferae arte cohaerentibus } & \ldots & \ldots & \ldots & \ldots\end{array}$ $\begin{array}{lllllllllllll}\ldots & \ldots & \ldots & \ldots & \ldots & \ldots & \text { Sectio Chamaedrys ... } & \ldots & \ldots & \ldots & \ldots & \ldots 24\end{array}$

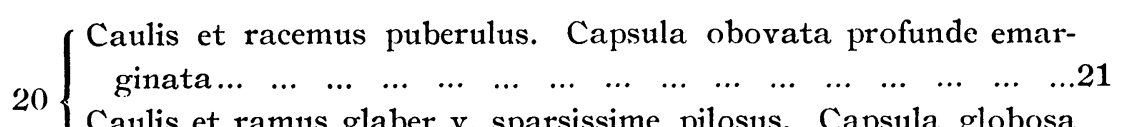

Caulis et ramus glaber v. sparsissime pilosus. Capsula globosa $\begin{array}{lllllllllllll}\text { apice } \operatorname{mucronata} \ldots & \ldots & \ldots & \ldots & \ldots & \ldots & \ldots & \ldots & \ldots & \ldots & \ldots & \ldots & \ldots 23\end{array}$

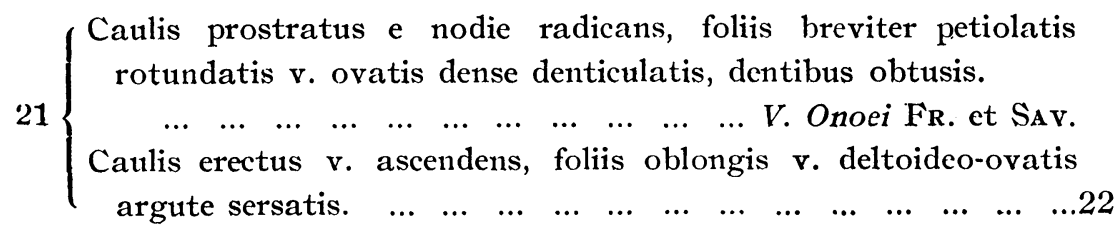
22\{
Folia ovato-oblonga inferior petiolata superior subsessilis. Racemi breves corymobosi pauciflori, bracteis quam pedicelli brevioribus.

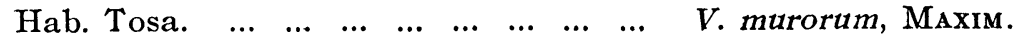
Folia sessilis v. brevissime petiolata ovata basi cordata, racemi elongati laxi, bracteis quam pedicelli plus minus longioribus. Capsula plano-compressa... 


\section{$23\left\{\begin{array}{l}\text { Folia sessilis amplexicaulis oblonga lanceolata, bractei lineares, } \\ \text { calycis segmentis quam capsula brevioribus ... V. Anagallis, L. }\end{array}\right.$ \\ Folia sessilis imis rarissime breviter petiolata ovato-oblonga cuneato-serrata, racemi longe pedunculati, calycis segmentis quam capsula longioribus...V. Beccabunga var. americana, Gı.EHN.}

Caulis ascendens $\mathbf{v}$. decumbens, foliis subrosulatis obovatis $\mathbf{v}$. ellipticis obtuse serratis cum caule pilosis, pilis longiusculis glandulosis. Racemi longe pedunculati, pedicellis quam bractei et colyces longioribus. Hab. Simshu.

$\begin{array}{lllllllll}\ldots & \ldots & \ldots & \ldots & \ldots & \ldots & \ldots & \text { V. aphylla var. grandiflora, BeNTH. }\end{array}$

Caulis ascendens $\mathbf{v}$. decumbens. Folia ovata serrata cum caule

24 sparsissime pilosa. Racemi floriferi breves corymbosi, fructiferi $\begin{array}{llllllllllll}\text { elongati laxi } & \ldots & \ldots & \ldots & \ldots & \ldots & \ldots & \ldots & \ldots & \ldots & \ldots & V \text {. cana, WALL. }\end{array}$

a. Racemi breves 1-2 v. pauciflori.

b. Caulis decumbens basi nodie radicans, foliis cum caule densiuscule pilosis $2 \mathrm{~cm}$. longis et $1 \frac{1 / 2}{\mathrm{~cm}}$. latis. Racemi

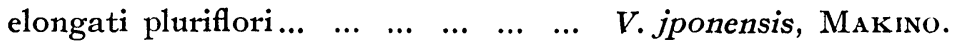

Yeronica sibilica, Linn. Bentham: DC. Prodr. X. 464; Ledeb.: F1. Ros. III. 229 ; Fr. Schmidt: Reis Amur. u. Sach. 57 ; 162.

$V$. vérginiana (non Linn.). Matsumura: Shokubutsumeikan. Phan. II. 574 .

Nom. Jap. Yezo no kugaisō エゾノクガイサウ.

Hab. Yezo.

var. japonica, NakAI: Cat. Sem. in Hort. Bot. Univ. Imp. Tokyo (1914) 33.

V. virginiana, Linn. Thunb.: Fl. Jap. 20 ; Mrquel : Prol. 50 ; Fra. et Sav. Enum. I 347 ; Matsumura : Shokubutsumeikan. Phan. II. 574.

Nom. Jap. Kugaiso クガイサウ.

Hab. Honto.

Veronica tryphyllos, Linn. Bentham : DC. Prodr. X. 485 ; Ledeb.: F1. Ros. III. 252; Matsumura: Shokubutsumeikan. Phan. II. 572.

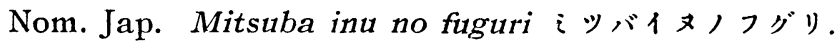

Hab. Introd.

Velonica Tournefortii, Gmel. Wettstein : Eng. u. Pr. Natur. Pfl. IV. 3b. 85 ; Matsumura : Shokubutsumeikan. Phan. II. 573.

V. buxbaumi, Ten. Bentham : DC. Prodr. X. 467 ; Ledeb.: Fl. Ros. III. 253.

Nom. Jap. Oinu fuguriオホイヌフグリ.

Hab. Introd. 
Veronica polita, Fr. LehmanN : Bull. 1'Herb. Bois. (1907) 557 ; Wettstein : Eng. u: Pr. Natur. Pf. IV. 3b. 85 ; Matsumura : Shokubutsumeikan. Phan. II. 552.

V. agrestis, Linn. Miquel : Prol. 52 ; Fr. SAv.: Enum. I. 350.

$V$. hederaffolia, Mrquel : Pro1. 361 ; Fr. et Sav. : 1. c.

Nom. Jap. Inu no fuguri イヌノフグリ.

Hab. Honto; Shikoku ; Kyūshū ; Yezo.

Yeronica incana, Linn. Bentham: DC. Prodr. X. 466 ; Ledeb. Fl. Ros. III. 235 ; Miquel : Prol. 52 ; Fr. et SAv. I. 348 ; Y. Iinuma : Sömokudzusetsu (Makino Rev.) pl. 15; Matsumura: Shokubutsumeikan. Phan. II. 572.

Nom. Jap. Tōteiran タウティラン.

Hab. Tango.

Veronica Sieboldiana, MrQ. Prol. 51 ; Fr. et SAv. : Enum. I 348. var. integrifolia, Maxim. Matsumura : Shokubutsumeikan Phan. II. 573.

Nom. Jap. Hamatora no wo ハァトラノキ.

Hab.

Yeronica Kiusiana, sp. nov.

V. ovatae NAKAI affinis sed exqua differt foliis acutior serratis, pedicellis quam bracteae multo longioribus, floribus majoribus. Planta perennis caule erecto simplice vel rarissime inferne ramoso villoso-pubescenti sesqui vel duo pedes alto. Folia inferiora petiolis leviter alatis pubescentibus, lamina deltoideo-ovata basi leviter cordata $v$. truncata cuneatisve, apice acuta vel plus minus obtusa margine subduplicato serrata dentibus acutis, sparse pilosa $5-7 \mathrm{~cm}$. longa et $3-3 \frac{1}{2} \mathrm{~cm}$. lata. Folia superiora breviter petiolata ovata vel ovato-acuminata basi rotundata argute serrata pilosa $3-3 \frac{1}{2} \mathrm{~cm}$. longa et $2-2 \frac{1}{2} \mathrm{~cm}$. lata. Inflorescentia elongata densiflora, foribus longe pedicellatis, bracteis lauceolatis pedicellis multo brevioribus pilosis, pedicellis gracilibus pilosis vulgo $3-3 \frac{1}{2} \mathrm{~mm}$. longis, calyce campaunlato $3-4 \mathrm{~mm}$. longo 4-fido (rarissime cum corolla 3-fido), segmentis ovatis acutis margine pilosis, corolla caerulea breviter tubulosa tubo intus glanduloso-piloso, limbi laciniis rotundatis integris $4 \mathrm{~mm}$ longis et latis, staminibus corollam multo excedentibus filamentis glabris 10-12 mm. longis, stylo 9-10 mm. longo. Capsula obovata emarginata, capsula matura non vidi. 
Temp. Flor. August.

Nom. Jap. Hiroba toranowo ヒロバトラノタ.

Hab. Higo; Bungo.

Yeronica longifolia, Linn. Bentham: DC. Prodr. X. 455 ; Ledeb.: Fl. Ros. III. 232 ; Fr. et SAv.: Enum. I. 348 ; MiQuel : Prol. 51 ; Miyabe: Flo. Kuril. 253 ; Makino: T. B. M. X. 252 ; Matsumura : Shokubutsumeikan. Phan. II. 572 ; NAKAI : Fl. Kor. II. 129.

$\alpha$ typica.

Nom. Jap. Yama ruritora no wo ヤアルリトラノキ.

Hab. Honto: Mutsu ; Yezo: Woshima; Shiribeshi ; Ishikari ; Hidaka.

$\beta$ Grayi, Schmidt: Reis. Amur. u. Ins. Sach. 162; Makino: T.B.M. X. 252 ; Matsumura : Shokubutsumeikan. Phan. II. 572.

Nom. Jap. Yezo ruritora no wo エゾルリトラノキ.

Hab. Ishikari ; Hidaka.

$\gamma$ villosa, var. nov.

Folia cano-villosa anguste lanceolata basi cordata truncata v. rotundata dense denticulata vulgo $7-8 \mathrm{~cm}$. longa et $2 \frac{1}{2} \mathrm{~cm}$ lata, racemo elongato saepius pluris densifloro, pedicellis bracteis et calycibus 2-3 plo longioribus. Capsula calycem multo excedens globosa $3-3 \frac{1}{2} \mathrm{~mm}$. longa.

Nom. Jap. Birodo tora no wo ビロウドトラノ

Hab. Iwashiro.

Veronica subsessilis, (MrQ.) Furumi.

V. longifolia var. " subsessilis Miquel: Prol. 52; Makino: T.B.M. X 252 ; Matsumura : Shokubutsumeikan Phan. II 572.

Planta valida subglabra caule erecto sparsissime pilos $\theta$, foliis sessilibus $v$. rarissime breviter petiolatis amplexicaulibus, ovatis v. ovato-oblongis acutis argute serratis, subtus in nervis sparsissime pilosis vulgo $5-7 \mathrm{~cm}$. longis et $3-4 \mathrm{~cm}$. latis. Racemi elongati $5-40 \mathrm{~cm}$. longi densiflori, rachi cano-pubescenti, bracteis filiformibus quam pedicelli brevioribus $2 \mathrm{~mm}$. longis pubescentibus. Calyx pedicellum aequilongus pilosus et tenere ciliolatus, laciniis ovatis acutis. Corollae tubus quam limbi lobi et calyx brevior, limbi lobis subaequalibus oblongis. Stamina exserta. Capsula orbiculata emarginata bisulcata calycem aequilonga, seminibus numerosis.

Nom. Jap. Ruri toranowo ルリトラノキ.

Hab. 
Yeronica spuria, Linn. Ledeb.: Fl. Ros. III. 231; Makino: T.B.M. XIII. 112 ; MAtsumura : Shokubutsumeikan. Phan. II. 573.

var. paniculata, Maxim. Ledeb.: Fl. Ros. III. 231; Makino : T. B. M. XIII. 112 ; Hayata : Flo. Mont. Form. 175 ; Matsumura: Shokubutsumeikan. Phan. II. 573, Fr. Schmidt : Reis. Amur. u. Sacha1. 57.

V. spicata, Linn. Franch. SAv.: Enum. I 348.

$V$. paniculata, Linn. Franch. Sav.: 1. c.

Nom. Jap. Yama toranowo ヤマトラノキ.

Hab. Honto: Shinano; Kai; Suruga; Musashi ; Shikoku; Tosa;

Kyüshu: Ōsumi; Hyūga ; Higo ; Bungo ; Hizen.

var. augustifolia Benth. Leden.: Fl. Ros. III. 231; Makino: T.B.M. XIII. 113 ; Matsumura : Shokubutsumeikan Phan. II 573.

Nom. Jap. Hime toranowo ヒメトラノタ.

Hab. Honto : Idzumo; Shikoku: Tosa ; Kiusiu: Higo; Hizen.

Veronica serpyllifolia, Iinn. Bentham: DC. Prodr. X. 482 ; Ledeb.:Fl. Ros. III. 248; A. Gray: Syn. Fl. N. Am. II. i. 288; Hooker: Fl. Brit. Ind. IV. 296 ; Mryabe: Fl. Kuril. 254; Makino: T. B. M. XIX. 104; Matsumura : Shokubutsumeikan Phan. II. 573 ; NakaI: Fl. Kor. II 128.

Nom. Jap. Tengu kuwagata テングクハガタ.

Hab. Honto: Kai ; Hida; Shinano; Yezo : Kitami ; Kuril.

Veronica Stelleri, Pall. Bentham: DC. Prodr. X. 482; Ledeb.: F1. Ros. III. 247; Maximowicz: Mel. Bio. XII. 501; Mryabe: Fl. Kuril. 254 ; A. Gray : Syn. Fl. N. Am. II. i. 288 ; YABE: T. B. M. XVII. 25 ; Matsumura : Shokubutsumeikan. Phan. II. 578.

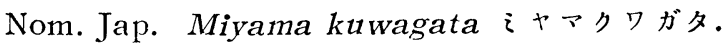

Hab. Honto: Iidesan; Mt. Shirouma; Tateyama ; Yezo: Rishiri (isl) ; Kuril.

Yeronica nipponica, Makino. Matsumura: Shokubutsumeikan Phan. II. 572.

Nom. Jap. Hime kuwagata ヒメ クガタ.

Hab. Chōkaizan ; Gwassan ; Hakusan (Kaga) ; Komagatake (Shinano).

Veronica Schmidtiana, Regel. Maximowicz: Mel. Bio. XII. 501 ; Fr. Schmidt: Reis. Amur. u. Ins. Sach. 162 ; Matsumura : Shokubutsumeikan. Phan. II. 573.

Nom. Jap. Miyama himetoranowo そヤマヒメトラ/タ.

Hab. Kuril. 
Veronica senanensis, Maxim. in Mel. Bio. XII. 768 ; Matsumura : Shokubutsumeikan Phan. II. 573.

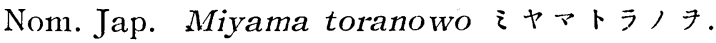

Hab. Mt. Bandai; Tokakushiyama; Mt. Shirouma ; Tateyama.

Veronica arvensis, Linn. Bentham : DC. Prodr. X 483 ; Leder. : F1. Ros. III. 249; A. Gray: Syn. Flo. N. Am. II. i. 288 ; Hooker: Fl. Brit. Ind. IV. 296 ; Matsumura : Shokubutsumeiken Phan. II. 571.

Nom. Jap. Tachi inu fuguri タチイヌフグリ.

Hab. Japonia.

Yeronica peregrina, Linn. Bentham: DC. Prodr. X. 482; Mrquel: Prol. 482; Fr. et Sav.: Enum. I. 349 ; A. Gray : Syn. Fl. N. Am. II. i. 288 ; Ledeb. : Fl. Ros. III. 249 ; Y. Iınuma : Sōmokudzusetsu (Makino rev.) vol. I. pl. 40 ; Matsumura : Shokubutsumeikan. Phan. II. 572.

Nom. Jap. Mushikusa ムシクサ.

Hab. Honto : Kōdzuke ; Sagami ; Bitchü ; Suoh; Shikoku : Tosa ; Kyūshü : Hyūga.

Veronica Oncei, Fr. et Sav. Enum. II. 457 ; Maximowicz: Mel. Bio. XII 501; Matsumura: Shokubutsumeikan Phan. II. 572.

Nom. Jap. Maruba kuwagata マルバクハガタ. Gumbai dzuru グンバイヅル.

Hab. Mt. Asama.

Yeronica murorum, Maxim. Mel. Bio. XI. 276 ; Másum. et Hay.: Enum. Form. 282; Matscmura : Shokubutsumeikan. Phan. II. 572.

Nom. Jap. Hama kuwagata ハアクハガタ.

Hab. Tosa.

Yeronica Thunbergii, A. Gray: On the Botany of Japan 402 ; Mrquel : Prol. 52; Fr. et Sav.: I. 349 ; II. 457 ; Matsumura : Shokubutsumeikan. Phan. II. 573.

Nom. Jap. Hiyoku sō ヒヨクサウ.

Hab. Honto: Kii ; Omi ; Kaga ; Shinano ; Uzen ; Yezo : Woshima ; Ishikari; Hidaka.

Veronica Anagallis, Linn. Bentham : DC. Prodr. X. 467 ; Ledeb.: Fl. Ros. III. 236 ; Hooker : Flo. Brit. Ind. IV. 294; A. Gray : Syn. F1. N. Am. II. i. 287 ; Thunberg : Fl. Jap. 20 ; Mrquel : Prol. 52 ; Fr. et Sav.: Enum. I. 349 ; Matsumura: Shokubutsumeikan Phan. II. 571 ; YABE : T. B. M. XVIII. 55 ; NAKAI : Fl. Kor. II. 128.

Nom. Jap. Kawajisa カハヂサ.

Hab. Honto: Musashi ; Shimoosa; Bitchū ; Aki ; Kyūshū : Chikuzen ; Tsushima.

Yeronica baccabunga, L. var. americana, Glehn. Maximowicz: 
Mel. Bio. XI. 278; Miyabe: Fl. Kuril. 253; Matsumura: Shokubutsumeikan. Phan. II. 571.

Nom. Jap. Yezo no kawajisa エゾノカハチサ.

Hab. Yezo.

Veronica aphylla var. grandiflora, Benth. Bentham : DC. Prodr. X. 476 ; Ledeb. : Fl. Ros. III. 245 ; Mryabe: Fl. Kuril. 253 ; MatsuMURA : Shokubutsumeikan. Phan. II. 571.

Nom. Jap. Simshu kuwagata シムシュクハガタ.

Hab. Simshu.

Yeronica cana, Wall. Bentham : DC. Prodr. X. 475 ; Hooker : Fl. Brit. Ind. IV. 295 ; Mrouel : Prol. 52 ; Fr. et SAv.: Enum. I. 349 ; Y. Induma : Sōmokudzusetsu (Makino rev.) vol. I. pl. 22 ; MatsuMURA : Shokubutsumeikan. Phan. II. 571.

Nom. Jap. Kuwagatasō クハガタサウ.

Hab. Honto : Sagami ; Musashi ; Shinano ; Kōdzuke ; Shimo dzuke ; Iwashiro; Shikoku : Tosa.

var. Takedana, Makino: T. B. M. XXI. 32 ; Matsumura: Shokubutsumeikan Phan. II. 571.

Nom. Jap. Kokuwagataso コクハガタサウ.

Hab. Shikoku: Tosa ; Awa.

Yeronica japonensis, Makino: T. B. M. XXVI. 148.

V. cana var. decumbens, Makino: T. B. M. XXI. 32 ; Matsumura: Shokubutsumeikan Phan. II. 571.

Nom. Jap. Yama-kuwagatasō ヤマクハガタサウ.

Hab. Ontake (Shinano Prov.)

Lagotis, GAERTN.

Maximowicz: Mel. Bio. XI. 296 ; Wettrstein : Eng. u. Pr.

Natur. Pf. IV. 3b. 86. (Gymnandra, PALL. in Selagineas.

Choisy : DC. Prodr. XII. 24; Benth. et Hook.: Gene. Pla.

1129 ; Ledeb. : Flo. Ros. III. 331.)

Lagotis glauca, Gaert. Maximowicz: Mel. Bio. XI. 296; WeTTStein : Eng. u. Pr. Natur. Pf. IV. 3b. 87 ; Matsumura : Shokubutsumeikan. Phan. II. 561.

Gymnandra Gmelini, Pall. Chorsy : DC. Prodr. XII. 25.

Nom. Jap. Urupso ウルツプサウ.

Hab. Honto: Shirouma; Kuril : Urup.

( To be continued.) 